ARTICLE

\title{
A natural light-driven inward proton pump
}

\author{
Keiichi Inoue ${ }^{1,2,3}$, Shota Ito ${ }^{1}$, Yoshitaka Kato ${ }^{1}$, Yurika Nomura' ${ }^{1}$ Mikihiro Shibata ${ }^{4,5}$, Takayuki Uchihashi ${ }^{4,5}$,
} Satoshi P. Tsunoda ${ }^{1} \&$ Hideki Kandori ${ }^{1,2}$

Light-driven outward $\mathrm{H}^{+}$pumps are widely distributed in nature, converting sunlight energy into proton motive force. Here we report the characterization of an oppositely directed $\mathrm{H}^{+}$ pump with a similar architecture to outward pumps. A deep-ocean marine bacterium, Parvularcula oceani, contains three rhodopsins, one of which functions as a light-driven inward $\mathrm{H}^{+}$pump when expressed in Escherichia coli and mouse neural cells. Detailed mechanistic analyses of the purified proteins reveal that small differences in the interactions established at the active centre determine the direction of primary $\mathrm{H}^{+}$transfer. Outward $\mathrm{H}^{+}$pumps establish strong electrostatic interactions between the primary $\mathrm{H}^{+}$donor and the extracellular acceptor. In the inward $\mathrm{H}^{+}$pump these electrostatic interactions are weaker, inducing a more relaxed chromophore structure that leads to the long-distance transfer of $\mathrm{H}^{+}$to the cytoplasmic side. These results demonstrate an elaborate molecular design to control the direction of $\mathrm{H}^{+}$transfers in proteins.

\footnotetext{
${ }^{1}$ Department of Life Science and Applied Chemistry, Nagoya Institute of Technology, Showa-ku, Nagoya 466-8555, Japan. ${ }^{2}$ OptoBioTechnology Research Center, Nagoya Institute of Technology, Showa-ku, Nagoya 466-8555, Japan. ${ }^{3}$ PRESTO, Japan Science and Technology Agency, 4-1-8 Honcho, Kawaguchi, Saitama 332-0012, Japan. ${ }^{4}$ Department of Physics, Kanazawa University, Kanazawa 920-1192, Japan. ${ }^{5}$ Bio-AFM Frontier Research Center, Kanazawa University, Kanazawa 920-1192, Japan. Correspondence and requests for materials should be addressed to H.K. (email: kandori@nitech.ac.jp).
} 
M icroorganisms utilize ion-transporting rhodopsins such as light-driven pumps and light-gated channels for electrochemical membrane potential generation and signal transduction, respectively ${ }^{1}$. These rhodopsins are also important tools for optogenetics, which control neural activity by light ${ }^{2}$. While light-driven outward $\mathrm{H}^{+}$and inward $\mathrm{Cl}^{-}$pumps were discovered in the last century ${ }^{3-5}$, more recent metagenomic analyses led to the discovery of an outward $\mathrm{Na}^{+}$pump $^{6}$, and cation $^{7,8}$ and anion channels 9 . Figure 1 summarizes the functions of ion-transporting rhodopsins in which transport is uni-directional for pumps and bi-directional for channels ${ }^{1}$. The direction of transport for known retinal-binding ion pumps is exclusively outward for cations and inward for anions, increasing membrane potential. The presence of inward cation and outward anion pumps is highly unlikely in nature, as it is energetically unfavourable.

Previously, we engineered inward $\mathrm{H}^{+}$transport by mutating Anabaena sensory rhodopsin $(\mathrm{ASR})^{10}$, a photochromic light sensor. Wild-type ASR does not transport ions, but an ASR mutant (D217E) exhibited light-induced inward $\mathrm{H}^{+}$transport when expressed in Escherichia coli cells. D217 is located in the cytoplasmic region of ASR, and light-induced difference Fourier transform infrared (FTIR) spectroscopy clearly showed an increased proton affinity for E217, which presumably controls the unusual directionality opposite to that in normal proton pumps. However, in that paper, we could not determine if the mutant functioned as an $\mathrm{H}^{+}$ pump or channel as the inside of the cell was negatively charged. On a related note, conversions of light-driven outward $\mathrm{H}^{+}$ pumps into an $\mathrm{H}^{+}$channel by mutation were reported recently ${ }^{11,12}$.

Here we report that a microbial rhodopsin from a deep-ocean marine bacterium, Parvularcula oceani, functions as inward $\mathrm{H}^{+}$ pump when expressed in E. coli and mouse neural cells. Mechanistic analyses of purified proteins reveal that the retinal chromophore structure and primary photoisomerization $\left(\mathrm{C}_{13}=\mathrm{C}_{14}\right.$ trans to $\left.c i s\right)$ are identical between outward and inward $\mathrm{H}^{+}$pumps. Nevertheless, the direction of primary $\mathrm{H}^{+}$transfer differs because of different electrostatic interactions of the protonated Schiff base with its counterion. We discuss these findings in terms of the molecular mechanisms of light-driven inward and outward $\mathrm{H}^{+}$pumps.

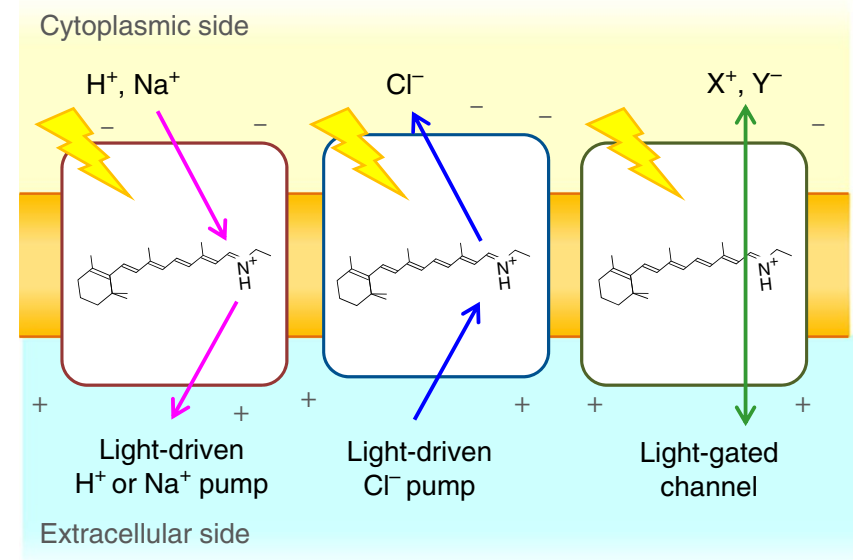

Figure 1 | lon-transporting microbial rhodopsins. Light-driven outward cation pumps (left) and inward anion pumps (middle) function as active transporters, while light-gated channels conduct cations or anions in a passive manner (right).

\section{Results}

PoXeR is a light-driven inward $\mathrm{H}^{+}$pump. P. oceani is an $\alpha$-proteobacterium found at a depth of $800 \mathrm{~m}$ in the south-eastern Pacific ocean. Analysis of the genome of $P$. oceani showed the existence of three microbial rhodopsins ${ }^{13}$. Two rhodopsins contain the NDQ and NTQ motifs, suggesting light-driven outward $\mathrm{Na}^{+}\left(\right.$PoNaR) and inward $\mathrm{Cl}^{-}{ }^{-}$(PoClR) transport, respectively (Fig. 2). The remaining rhodopsin possesses the DTL motif (Fig. 2a) and has amino-acid sequence $51 \%$ identical to that of $\mathrm{ASR}^{14}$, a photochromic light sensor (Supplementary Fig. 1). Nevertheless, unlike ASR, this rhodopsin does not contain a long Arg-rich C-terminus (Supplementary Fig. 1), and can be classified as a xenorhodopsin (XeR), whose function is unknown ${ }^{15}$ (Supplementary Fig. 1). Thus, unlike many microbes that normally contain an $\mathrm{H}^{+}$pump, $P$. oceani does not seem to have one. Instead, it has an $\mathrm{Na}^{+}$pump $(P o N a R), \mathrm{Cl}^{-}$pump $(\mathrm{PoClR})$ and rhodopsin of an unidentified function (PoXeR).

We tested the ion-transporting functions of these rhodopsins using heterologous expression of C-terminally his-tagged proteins in E. coli. The membranes of PoNaR-expressing bacteria were yellow (Fig. 3a), suggesting low expression or improper folding of the protein. In contrast, $\mathrm{PoClR}$ and $\mathrm{PoXeR}$ formed red/purple pigment (Fig. 3a). Next, we examined their ion-pumping activities. For PoClR-expressing cells, we observed a light-induced increase in $\mathrm{pH}$, which was accelerated by carbonylcyanide-mchlorophenylhydrazone (CCCP) (Fig. 3a). This $\mathrm{pH}$ increase was similar in $\mathrm{NaCl}$ and $\mathrm{CsCl}$, but was abolished when $\mathrm{Na}_{2} \mathrm{SO}_{4}$ was used. Strong anion dependence is fully consistent with the inward $\mathrm{Cl}^{-}$pump function of PoClR. For PoXeR-expressing cells, we also observed a light-induced $\mathrm{pH}$ increase in all salts, but the signals disappeared in the presence of CCCP (Fig. 3a). This suggests inward $\mathrm{H}^{+}$transport driven by light for PoXeR. Even though ASR does not transport ions ${ }^{14}$, we engineered inward $\mathrm{H}^{+}$ transport of an ASR mutant (D217E) by light ${ }^{10}$. However, it was not clear D217E ASR is an inward $\mathrm{H}^{+}$pump or channel, because the inside of the cell is negatively charged. To verify the active nature of inward proton transport, voltage and current across the membrane should be controlled. For this purpose, we expressed PoXeR in mouse ND7/23 cells and performed electrophysiological measurements. The data in Fig. 3b display an inward current for all measured membrane voltages (from $-55 \mathrm{mV}$ to $45 \mathrm{mV}$ ). More importantly, the obtained $I-V$ curve was identical for different extracellular $\mathrm{pH}$ values (7.2 and 9.0), typical for light-driven $\mathrm{H}^{+}$pumps. Thus, despite the lack of measurements in native cells, the results in E. coli and ND7/23 cells strongly suggest that $P o X e R$ is a natural light-driven inward $\mathrm{H}^{+}$pump.

Molecular properties of PoXeR. The unusual inward $\mathrm{H}^{+}$ pumping activity of PoXeR poses questions about its physiological role and molecular mechanism. The former is difficult to address as the culture of native cells is not available. As for the latter, we studied the molecular mechanism of the inward $\mathrm{H}^{+}$ pumping by various spectroscopic methods using PoXeR expressed in E. coli.

Figure 4a shows the absorption spectrum of PoXeR $\left(\lambda_{\max }=567\right.$ $\mathrm{nm}$ ) in the dark and after illumination, and a high-speed atomic force microscopy (AFM) image (Fig. 4b) shows that PoXeR forms a trimer in the nanodisk membrane. ASR contains predominantly all-trans chromophore in the dark but the 13-cis, 15-syn chromophore is formed after light-adaptation ${ }^{16,17}$. This is also the case for PoXeR, which is $92 \%$ all-trans in the dark while all-trans and 13-cis forms are equally distributed after the illumination (Fig. 4c). Calculated absorption spectra of all-trans and 13-cis forms exhibit $\lambda_{\max }$ at 568 and $549 \mathrm{~nm}$, respectively, similar to those observed for ASR $^{18}$. 
a

\begin{tabular}{|c|c|c|c|c|c|c|c|c|c|c|}
\hline Residue number of BR & 82 & 85 & 89 & 96 & 115 & 194 & 204 & 212 & 216 & 223 \\
\hline Residue number of $P o R 3$ & 71 & 74 & 78 & 85 & 108 & 187 & 197 & 205 & 209 & 216 \\
\hline BR & $\mathbf{R}$ & D & $\mathbf{T}$ & D & D & $E$ & E & D & $\mathbf{K}$ & $\mathbf{L}$ \\
\hline KR2 & $\mathbf{R}$ & $\mathbf{N}$ & D & $\mathbf{Q}$ & G & $\mathbf{F}$ & $\mathbf{R}$ & D & K & $\mathbf{L}$ \\
\hline PoR1 (PoNaR) & $\mathbf{R}$ & N & D & $Q$ & G & $\mathbf{I}$ & $\mathbf{R}$ & D & $\mathbf{K}$ & $\mathbf{L}$ \\
\hline FR & $\mathbf{R}$ & $\mathbf{N}$ & $\mathbf{T}$ & Q & A & $\mathbf{L}$ & $\mathbf{R}$ & D & $\mathbf{K}$ & $\mathbf{L}$ \\
\hline PoR2 (PoCIR) & $\mathbf{R}$ & $\mathbf{N}$ & $\mathbf{T}$ & Q & A & $\mathbf{F}$ & $\mathbf{R}$ & D & K & $\mathbf{L}$ \\
\hline PoR3 (PoXeR) & $\mathbf{R}$ & D & $\mathbf{T}$ & $\mathbf{L}$ & D & $\mathbf{S}$ & S & $\mathbf{P}$ & $\mathbf{K}$ & Di \\
\hline ASR & $\mathbf{R}$ & D & $\mathbf{T}$ & $\mathrm{s}$ & $\mathbf{Q}$ & $s$ & D & $\mathbf{P}$ & $\mathrm{K}$ & D \\
\hline
\end{tabular}

b

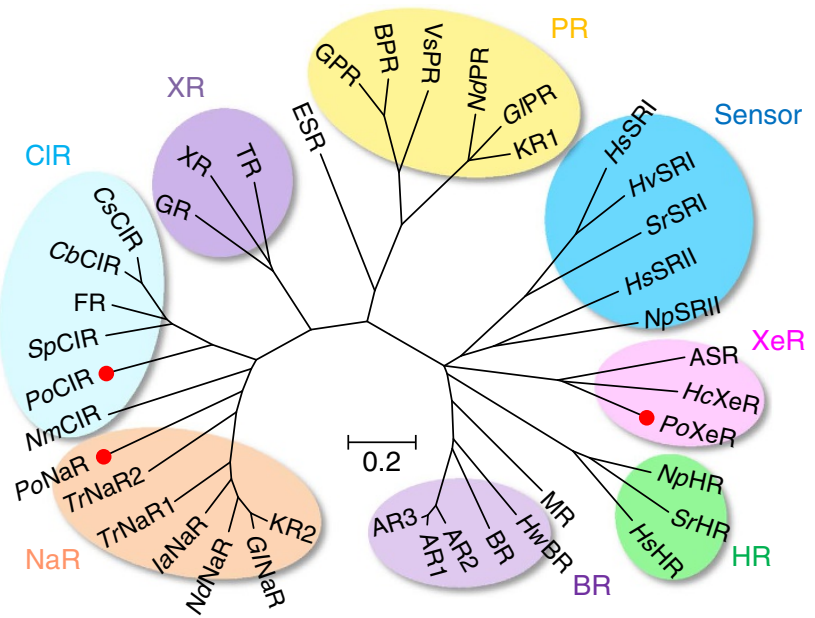

Figure 2 | Amino-acid sequence alignment of important residues and phylogenetic tree of microbial rhodopsins. (a) Important residues for the function of microbial rhodopsins. BR, KR2, FR and ASR are outward $\mathrm{H}^{+}$ pump, outward $\mathrm{Na}^{+}$pump, inward $\mathrm{Cl}^{-}$pump, and photochromic sensor, respectively. Dashed rectangles indicate the positions of NDQ and NTQ motifs and residues unique for XeR. (b) Phylogenetic tree of selected microbial rhodopsins. The rhodopsins included in the phylogenetic tree: bacteriorhodopsin from Halobacterium salinarum (BR), archaerhodopsin-1, -2 and -3 from Halorubrum sodomense (AR1, AR2 and AR3), bacteriorhodopsin and middle rhodopsin from Haloquadratum walsbyi (HwBR, MR),

halorhodopsin from $H$. salinarum, Salinibacter ruber and Natronomonas pharaonis (HsHR, SrHR, NpHR), PoXeR, xenorhodopsin from Haloplasma contractile ( $H c X e R), A S R$, sensory rhodopsin II from N. pharaonis and $H$. salinarum (NpSRII and HsSRII), sensory rhodopsin I from S. ruber, Haloarcula vallismortis and $\mathrm{H}$. salinarum ( $\mathrm{SrSRI}, \mathrm{HvSRI}$ and $\mathrm{HsSRI}$ ), proteorhodopsin from Krokinobacter eikastus, Gillisia limnaea, Nonlabens dokdonensis and Vibrio sp. AND4 (KR1, GIPR, NdPR, VsPR), blue-absorbing proteorhodopsin from uncultured bacterium (BPR), green-absorbing proteorhodopsin from uncultured marine gamma proteobacterium (GPR), rhodopsin from Exiguobacterium sibiricum (ESR), thermophilic rhodopsin from Thermus thermophilus (TR), xanthorhodopsin from S. ruber (XR), rhodopsin from Gloeobacter violaceus $P C C 7421(\mathrm{GR})$, putative $\mathrm{Cl}^{-}$pumping rhodopsin from Citromicrobium sp. JLT1363, Citromicrobium bathyomarinum and Sphingopyxis baekryungensis (CsCIR, CbCIR, SpCIR), $\mathrm{Cl}^{-}$pump from Fulvimarina pelagi and Nonlabens marinus S1-08 (FR and NmCIR), PoCIR, PoNaR, two putative NaRs from Truepera radiovictrix (TrNaR1 and TrNaR2), putative NaR from Indibacter alkaliphilus (laNaR), NaR from N. dokdonensis, G. limnaea and K. eikastus (NdNaR, G/NaR and KR2).

Photoreaction dynamics of a dark-adapted PoXeR. We next studied the photocycle of the dark-adapted PoXeR protein, which presumably represents the inward $\mathrm{H}^{+}$pumping process. To avoid photoexcitation of the 13-cis form, we measured single-wavelength kinetics of a $0.6 \mathrm{ml}$ sample of dark-adapted protein, and replaced it after each single excitation measurement. Figure 5a shows the time-resolved difference spectra (left), absorption changes at each wavelength (centre) and decayassociated spectra (right). Upon photoexcitation of the all-trans form $\left(P o X e R_{\mathrm{AT}}\right)$, the red-shifted $\mathrm{K}$ intermediate appears first, and decays to the blue-shifted $\mathrm{L}$ intermediate in $2 \mu$ s. Then, the $\mathrm{M}$ intermediate containing a deprotonated Schiff base appears with two distinct time-constants $(210 \mu \mathrm{s}$ and $6.0 \mathrm{~ms})$. This analysis shows the presence of two states for $\mathrm{L}$ and $\mathrm{M}$, one of which is in equilibrium. The M-intermediate decays in $200 \mathrm{~ms}$, but the transient absorption does not return to zero (Fig. 5a, centre) at $>1 \mathrm{~s}$, indicating the presence of another long-lived intermediate state. The difference spectrum obtained by transient absorption spectroscopy (spectrum at $2 \mathrm{~s}$ in Fig. $5 \mathrm{a}$, left) coincides with that obtained by steady-state absorption measurements in Fig. 4a (Fig. 5a, inset). Therefore, the last intermediate represents metastable 13-cis state $\left(P_{o X e R_{13 C}}\right)$ that reverts into $P_{0 X e R_{A T}}$ in $91 \mathrm{~s}$ (Fig. 5b). The photocycle of $P o X e R_{\mathrm{AT}}$ is summarized in Fig. 5c: the inward $\mathrm{H}^{+}$transport is made possible by (i) $\mathrm{H}^{+}$ release from the Schiff base to the cytoplasmic region upon $\mathrm{M}$ formation and (ii) $\mathrm{H}^{+}$uptake from the extracellular region upon $\mathrm{M}$ decay.

$\mathrm{H}^{+}$pathway during the inward transport in PoXeR. As light-driven outward $\mathrm{H}^{+}$pumps contain internal $\mathrm{H}^{+}$acceptors and donors ${ }^{1}$, we examined candidates for such groups for the inward $\mathrm{H}^{+}$pump. Membrane-embedded carboxylates are strong candidates for internal $\mathrm{H}^{+}$acceptors and donors, as is the case for D85 (acceptor) and D96 (donor) in an outward $\mathrm{H}^{+}$pump BR (refs 19,20). Figure 6a shows putative location of eight intramembrane carboxylates possibly involved in the transport, which we replaced with neutral residues (D-to-N or E-to-Q). Among the mutants, only D74N showed the absence of colour. As D74 acts as the counterion of the protonated Schiff base, we attempted a more conservative replacement, D74E. The inward $\mathrm{H}^{+}$pumping activity was measured for various mutants (Fig. 6b), and the initial slopes are plotted in Fig. 6c.

The results clearly show a significant reduction in the pumping activity in E35D/Q, D74E, D108E/N and D216N. In contrast, D216E showed about threefold higher inward $\mathrm{H}^{+}$pumping activity than wildtype (WT). It should be noted that the corresponding mutant of ASR (D217E) shows inward $\mathrm{H}^{+}$ transport ${ }^{10}$. Previously, light-induced difference FTIR spectroscopy of D217E ASR revealed protonation of E217 upon deprotonation of the Schiff base $(\mathrm{M} \text { intermediate })^{10}$. Here we applied similar FTIR analysis to PoXeR $_{\mathrm{AT}}$ (Supplementary Fig. 2). The top panel of Fig. $6 \mathrm{~d}$ shows a positive peak at $1,736 \mathrm{~cm}^{-1}$, which down-shifts to $1,726 \mathrm{~cm}^{-1}$ in $\mathrm{D}_{2} \mathrm{O}$ in the M-minus$P_{o X e R_{A T}}$ difference spectra. This is a characteristic signal of protonated carboxylic acids, indicating that carboxylate is the $\mathrm{H}^{+}$ acceptor of the Schiff base. Similar positive peaks were observed for D74E and D108N, but an entirely different spectral feature was obtained for D216E. Sharp positive peaks of WT at 1,736 and $1,726 \mathrm{~cm}^{-1}$ in $\mathrm{H}_{2} \mathrm{O}$ and $\mathrm{D}_{2} \mathrm{O}$ were shifted to 1,719 and $1,708 \mathrm{~cm}^{-1}$ in $\mathrm{D} 216 \mathrm{E}$, respectively, and the remaining pair of peaks at $1740(-) / 1734(+) \mathrm{cm}^{-1}$ in $\mathrm{H}_{2} \mathrm{O}(1,730(-) / 1,725$ $(+) \mathrm{cm}^{-1}$ in $\left.\mathrm{D}_{2} \mathrm{O}\right)$ originates from a different carboxylic acid. This strongly suggests that $\mathrm{D} 216$ is the $\mathrm{H}^{+}$acceptor during the inward $\mathrm{H}^{+}$transport in PoXeR. In agreement with that idea, the positive peak at $1,736 \mathrm{~cm}^{-1}$ was absent in D216N. In contrast, a positive peak was observed at $1,188 \mathrm{~cm}^{-1}$ in the $\mathrm{C}-\mathrm{C}$ stretching region of retinal chromophore, indicating that the $\mathrm{M}$ intermediate did not form in D216N. There was no positive peak in the frequency region of protonated carboxylic acids and the $1,188 \mathrm{~cm}^{-1}$ band was present (no $\mathrm{M}$ formation) in $\mathrm{E} 35 \mathrm{Q} / \mathrm{D}$ as 

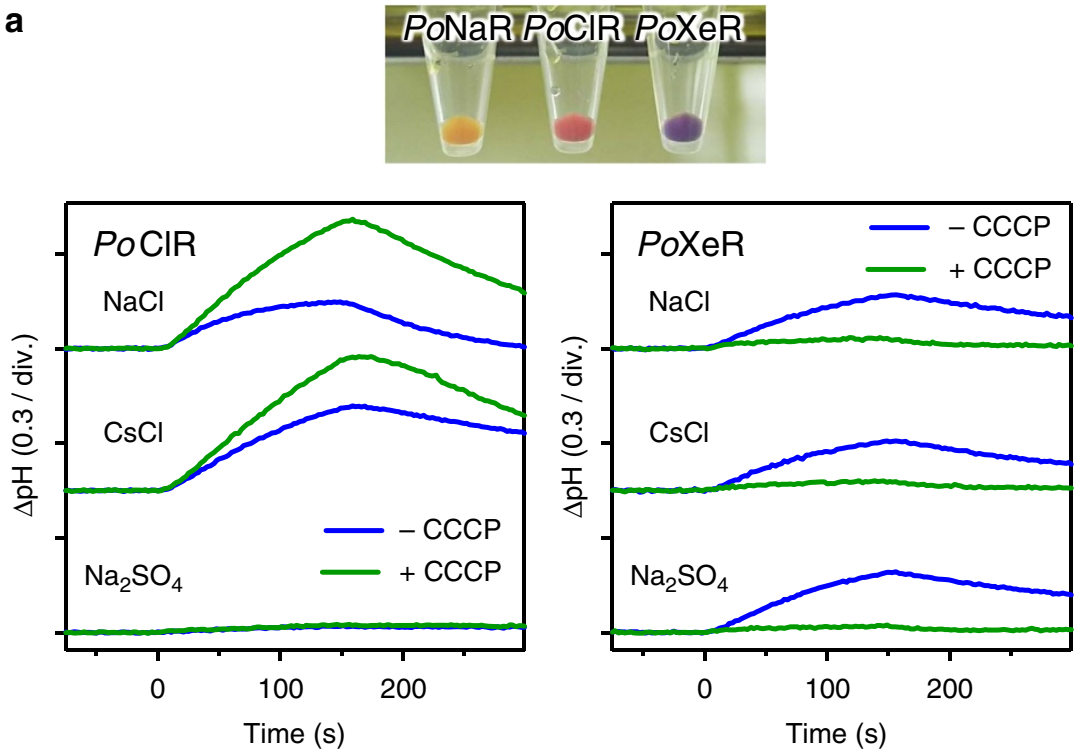

b

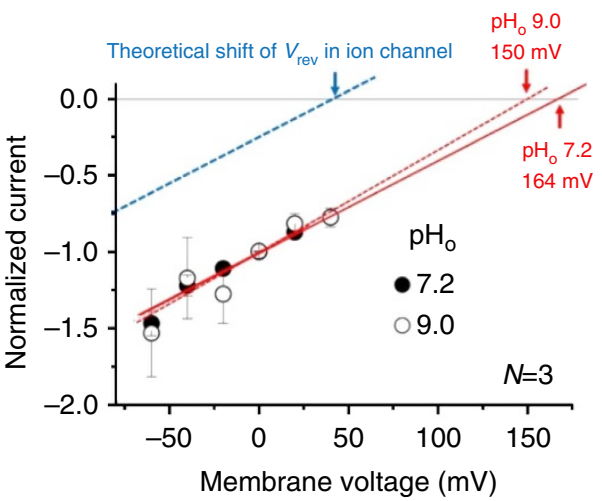

Figure 3 | Light-driven $\mathbf{H}^{+}$transport activity of PoXeR. (a) E. coli C43(DE3) strain cells in which the expression of PoNaR, PoCIR and PoXeR was induced (upper), and ion-pumping activity was assayed by observing $\mathrm{pH}$ changes (lower). Light is on between 0 and $150 \mathrm{~s}$. (b) Electrophysiological measurements of PoXeR-driven photocurrent in ND7/23 cells (left) and $I-V$ plot of the current at $\mathrm{pH}_{\circ} 7.2$ and 9.0.

well. From homology modelling, E35 is likely to be located near D216, and the E35 mutation may raise the pKa of D216, leading to the lack of $\mathrm{M}$ formation. According to the structure of ASR, the distance between the Schiff base and D217 (D216 in PoXeR) is $14.7 \AA$ (ref. 21), and such long-range $\mathrm{H}^{+}$transfer should be mediated by other residues and/or water molecules in the inward $\mathrm{H}^{+}$pump.

As for the identity of $\mathrm{H}^{+}$donor to the Schiff base, the decay of the $\mathrm{M}$ intermediate accompanies protonation of the Schiff base, and if $\mathrm{H}^{+}$is taken up from the aqueous phase, the decay of $\mathrm{M}$ should slow down at high $\mathrm{pH}$ (ref. 22). We thus measured the M decay kinetics at different $\mathrm{pH}$ values. Figure $7 \mathrm{a}$ shows strong $\mathrm{pH}$ dependence of the $\mathrm{M}$ rise but limited $\mathrm{pH}$ dependence of the $\mathrm{M}$ decay. In fact, the speed of $\mathrm{M}$ decay increased at $\mathrm{pH} 9.0$. This fact indicates the presence of an internal $\mathrm{H}^{+}$donor. If it is a carboxylic acid, we expect a negative band in the 1,760$1,700 \mathrm{~cm}^{-1}$ region in the $P_{0 X e R_{13 C} \text {-minus-PoXeR }}$ AT difference FTIR spectra. However, Fig. $7 \mathrm{~b}$ shows a broad positive peak at $1,723 \mathrm{~cm}^{-1}$ in addition to a peak pair at $1,741(+) /$ $1,736(-) \mathrm{cm}^{-1}$. Absence of deprotonation signal in this region questions the role of a carboxylic acid as the $\mathrm{H}^{+}$donor. Other residues such as arginine and protein-bound water molecules are possible candidates for the internal $\mathrm{H}^{+}$donor ${ }^{23,24}$. The spectral features at $1,336(+) \mathrm{cm}^{-1}$ and $1,198(-) / 1,183(+) \mathrm{cm}^{-1}$ (Fig. $7 \mathrm{~b}$ and Supplementary Fig. 3) resemble those of the dark

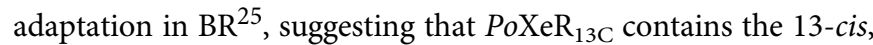
15-syn configuration.

\section{Discussion}

In this paper, we report the discovery and characterization of a natural retinal-binding inward $\mathrm{H}^{+}$pump (PoXeR). Mechanistic analyses of the purified protein revealed that the retinal chromophore structure and primary photoisomerization $\left(\mathrm{C}_{13}=\mathrm{C}_{14}\right.$ trans to cis $)$ are identical between outward and inward $\mathrm{H}^{+}$pumps. Nevertheless, direction of the primary $\mathrm{H}^{+}$transfer in PoXeR is opposite to that in outward $\mathrm{H}^{+}$pumps. The pathway of the inward $\mathrm{H}^{+}$transport in PoXeR is summarized in Fig. 8. The primary $\mathrm{H}^{+}$transfer occurs from the Schiff base to D216 on the cytoplasmic side. E35 modulates its $\mathrm{pKa}$ by forming hydrogenbonding network with D216, similar to the one reported for ASR (E36 and D217 $)^{26}$. Secondary $\mathrm{H}^{+}$transfer occurs from an unidentified group to the Schiff base on the extracellular side. This sequence of events in $\mathrm{H}^{+}$transport is entirely opposite to the one well-known for outward $\mathrm{H}^{+}$pumps such as $\mathrm{BR}^{1,27-33}$.

We suggest the following mechanism for the distinct vectoriality between PoXeR and BR transport (Fig. 9). Photoexcitation first converts the all-trans chromophore into a twisted 13-cis, 15-anti state in both, but its relaxation differs between BR and PoXeR. 
a

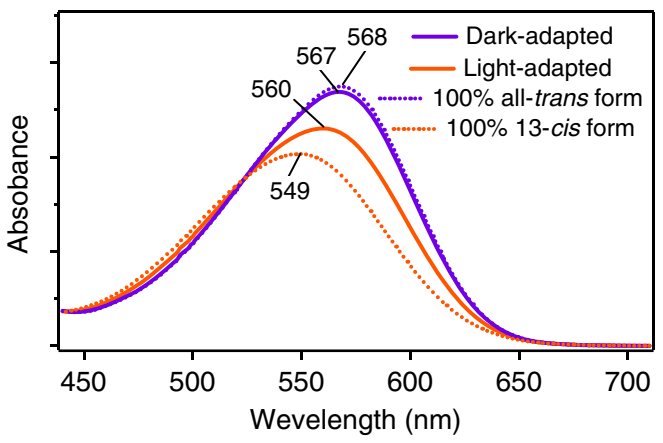

b

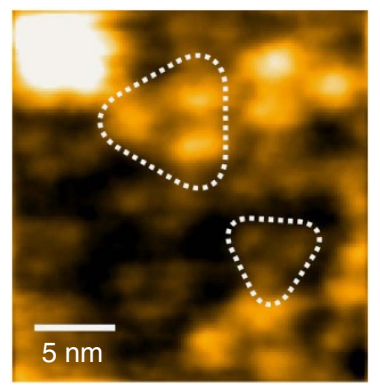

C

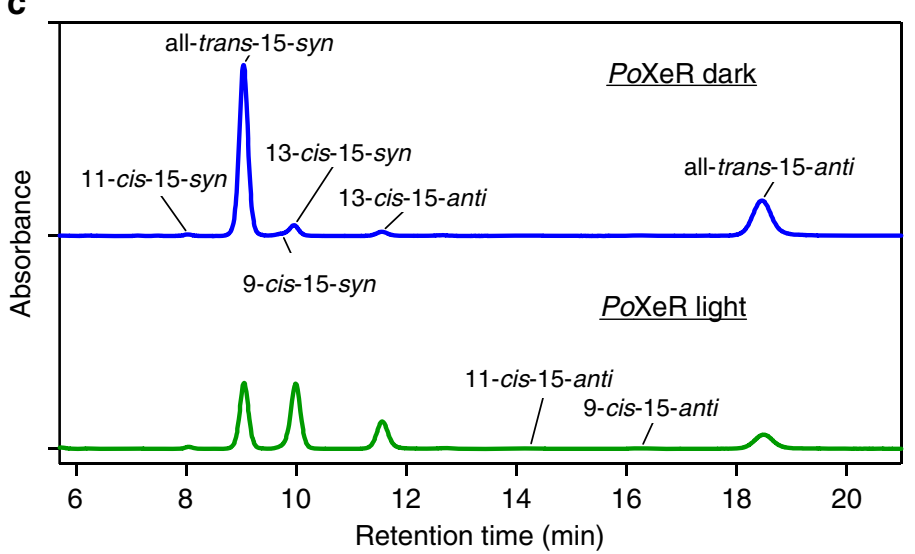

Figure 4 | Molecular properties of PoXeR. (a) Absorption spectra of dark- and light-adapted PoXeR (purple and orange solid lines, respectively). Dashed lines represent the calculated spectra of 100\% all-trans and 100\% 13-cis forms. (b) High-speed AFM image of PoXeR reconstituted in a nanodisc. (c) HPLC pattern of retinal extracted from PoXeR.

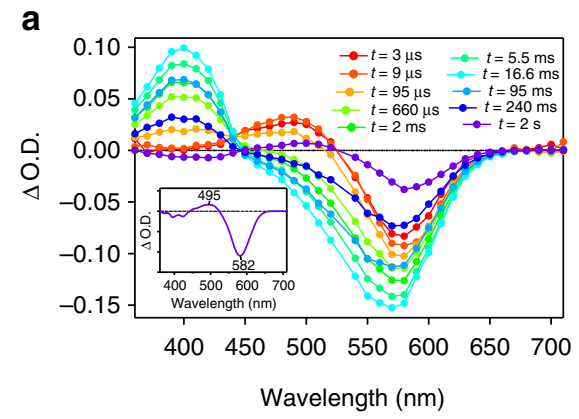

b

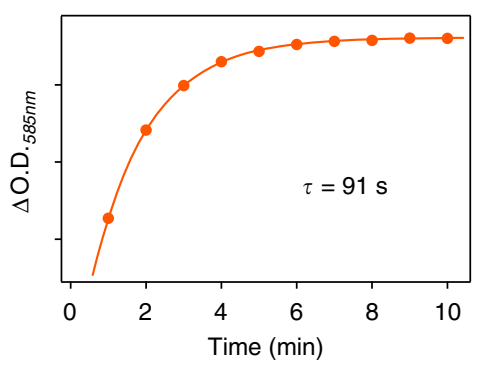

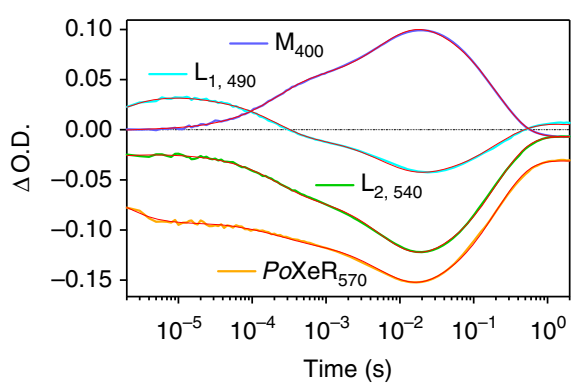

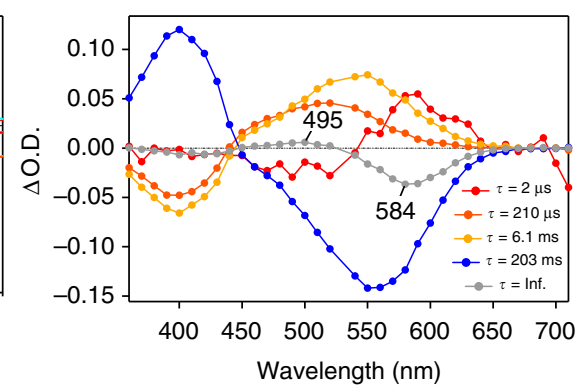

c

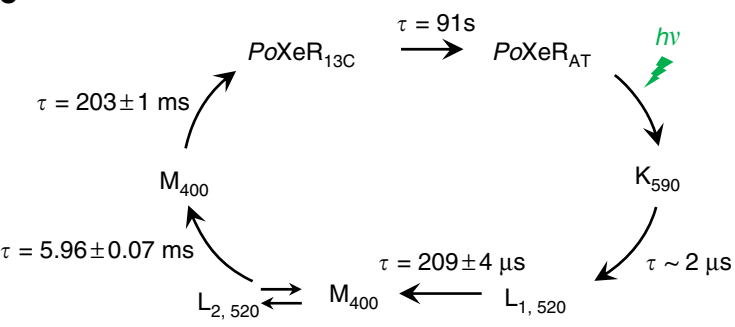

Figure 5 | Photoreaction dynamics of PoXeR. (a) Transient difference absorption spectra of dark-adapted PoXeR (left) and absorption difference time-evolution at specific wavelengths (centre). Decay-associated spectra obtained by global fitting of the changes in transient absorption (right). The inset shows the difference spectrum between light-adapted and dark-adapted state. (b) The process of dark-adaptation estimated by the recovery of absorption at $585 \mathrm{~nm}$. (c) The photocycle of PoXeR. Values of the time-constants of each process are the mean \pm s.d. 
a

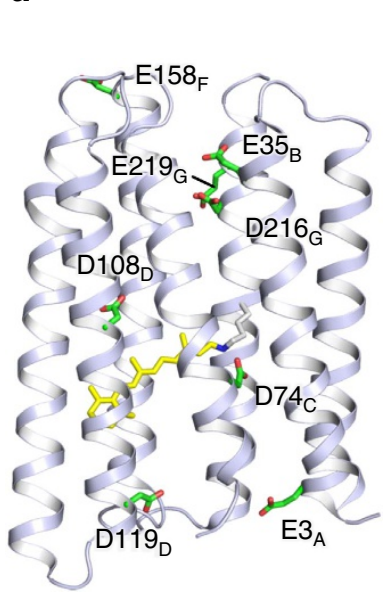

b

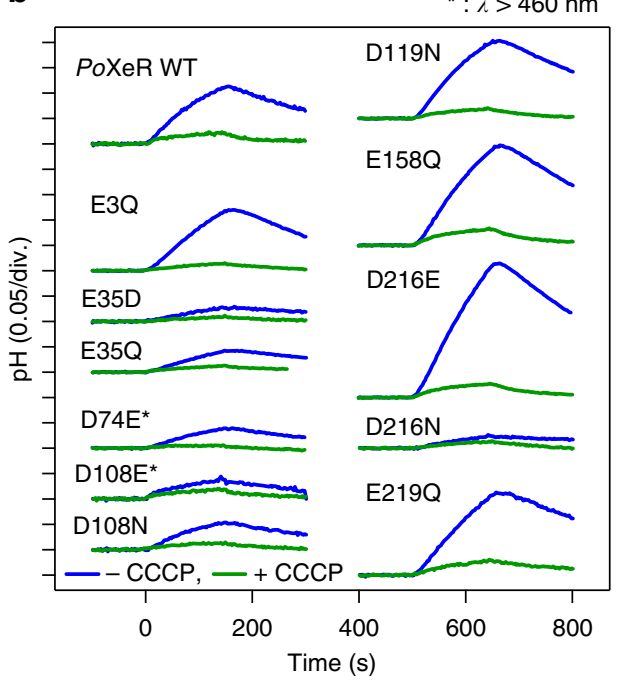

d

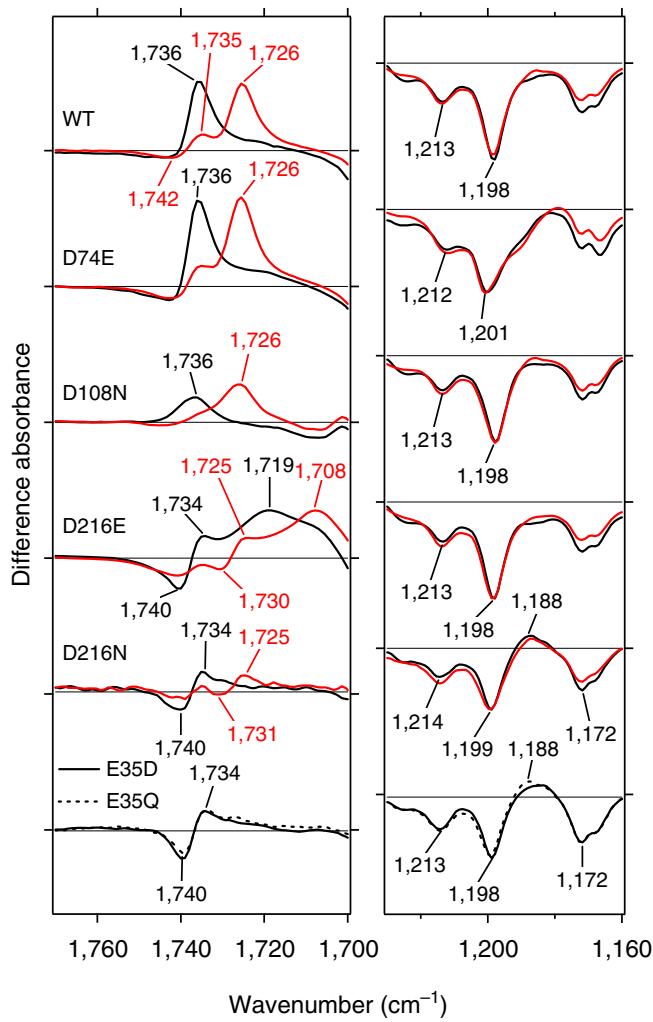

C

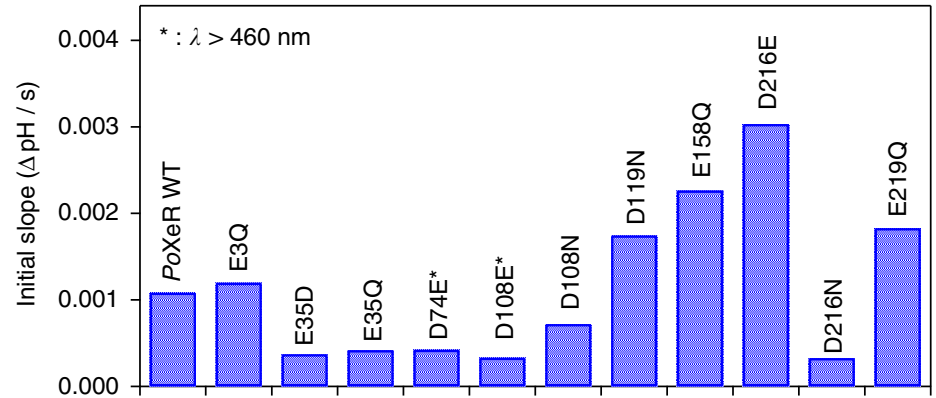

Figure 6 | Inward $\mathbf{H}^{+}$pumping activity and light-induced FTIR spectra of PoXeR and its mutants. (a) The crystal structure of ASR (PDB ID: $\left.1 X I O\right)^{21}$ is shown with the side chains of the acidic residues used in PoXeR mutagenesis studies. The residue numbering of PoXeR is shown. (b) $\mathrm{H}^{+}$transport activity of PoXeR mutants in E. coli cells after normalization for the amount of protein. Light is on between 0 and $150 \mathrm{~s}$. (c) The initial slopes of light-induced pH changes shown in b. (d) Light-induced difference FTIR spectra of WT PoXeR and the mutants at $T=230 \mathrm{~K}$ and pH 8.0. Spectra are measured in $\mathrm{H}_{2} \mathrm{O}\left(\right.$ black) and $\mathrm{D}_{2} \mathrm{O}$ (red).

There are two negative charges, D85 and D212, on the extracellular side of $\mathrm{BR}$, producing strong electrostatic attraction of the protonated Schiff base before the primary $\mathrm{H}^{+}$transfer, leading to outward $\mathrm{H}^{+}$transport ${ }^{34}$. In contrast, the XeR family possesses only one negative charge in that region, as D212 of BR is replaced by proline, which makes the electrostatic interaction between the protonated Schiff base and the counterion (D74 in PoXeR) weaker ${ }^{35-38}$. Consequently, photoisomerization reorients the $\mathrm{N}-\mathrm{H}$ group of the Schiff base toward the cytoplasmic side. The cytoplasmic domain is more polar in ASR than in $\mathrm{BR}^{21}$, and such a structure should promote long-distance $\mathrm{H}^{+}$transfer to D216 in PoXeR.

After the $\mathrm{M}$-intermediate formation, $\mathrm{BR}$ receives $\mathrm{H}^{+}$from the cytoplasmic side, followed by thermal isomerization to the original all-trans form. Therefore, only one double bond at $\mathrm{C}_{13}=\mathrm{C}_{14}$ bond isomerizes during the functional photocycle of BR. In contrast, after $M$ formation of $P o X e R$, it is likely that thermal isomerization occurs at $\mathrm{C}_{15}=\mathrm{N}$ bond from an anti to a syn form, followed by secondary $\mathrm{H}^{+}$transfer on the extracellular side. This yields a 13-cis, 15-syn form $\left(\right.$ PoXeR $\left._{13 \mathrm{C}}\right)$, and thermal bicycle-pedal isomerization ${ }^{39}$ (13-cis, 15-syn to all-trans, 15-anti) reverts it to the original state. Thermal isomerization of the $\mathrm{C}_{15}=\mathrm{N}$ group was known for $\mathrm{BR}$ as a dark-adaptation process ${ }^{25}$, but is directly related to the function of XeRs, such as ASR and PoXeR. In ASR, $\mathrm{C}_{15}=\mathrm{N}$ thermal isomerization after $\mathrm{C}_{13}=\mathrm{C}_{14}$ photoisomerization occurs with $100 \%$ yield, leading to an efficient photochromic reaction ${ }^{18,40}$. In $P o X e R, C_{15}=N$ thermal isomerization allows for an inward $\mathrm{H}^{+}$transport, an additional function for microbial rhodopsins, though the thermal isomerization yield is unknown at present.

Inward $\mathrm{H}^{+}$transport may lower the proton motive force, which is bioenergetically disadvantageous for marine bacteria. Thus, its presence in nature suggests a different physiological role, not related to bioenergetics. One possibility is that the inward $\mathrm{H}^{+}$ pump may be used for intracellular signal transduction, similar to $\mathrm{ASR}^{\mathrm{1}}$. A future structure-function study of PoXeR should lead to a better understanding of this unique function. The light-driven inward $\mathrm{H}^{+}$pump is also a potential tool for optogenetics. The light-driven outward $\mathrm{H}^{+}$pump Arch has been used as a neural silencer in optogenetics and Arch is also used for acidification of cell organelles ${ }^{41}$. An oppositely directed light-driven $\mathrm{H}^{+}$pump would further enable the control of cell organelles.

In summary, we show that PoXeR is a light-driven inward $\mathrm{H}^{+}$pump from a marine $\alpha$-proteobacterium. While outward $\mathrm{H}^{+}$ pumps are widely present in nature, oppositely directed $\mathrm{H}^{+}$ pumps are rare. In inward $\mathrm{H}^{+}$pumps, the lack of a negative charge in the active centre causes weak coupling to the Schiff base counterion (D74) in the key photocycle intermediate, leading to the release of $\mathrm{H}^{+}$to $\mathrm{D} 216$ in the cytoplasmic region. Retinal isomerization sequence became more complex to facilitate the inward $\mathrm{H}^{+}$transport: (i) $\mathrm{C}_{13}=\mathrm{C}_{14}$ trans to cis photoisomerization, (ii) $\mathrm{C}_{15}=\mathrm{N}$ anti to syn thermal isomerization and (iii) $\mathrm{C}_{13}=\mathrm{C}_{14}$ cis to trans and $\mathrm{C}_{15}=\mathrm{N}$ syn to anti thermal isomerization by a bicycle-pedal motion ${ }^{39}$. This work demonstrates an elaborate molecular design to control the direction of $\mathrm{H}^{+}$transport in retinal-binding proteins. The 
a

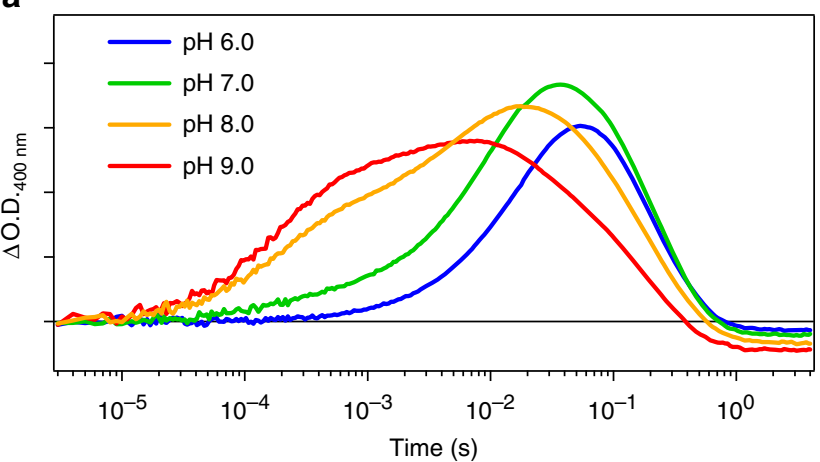

b

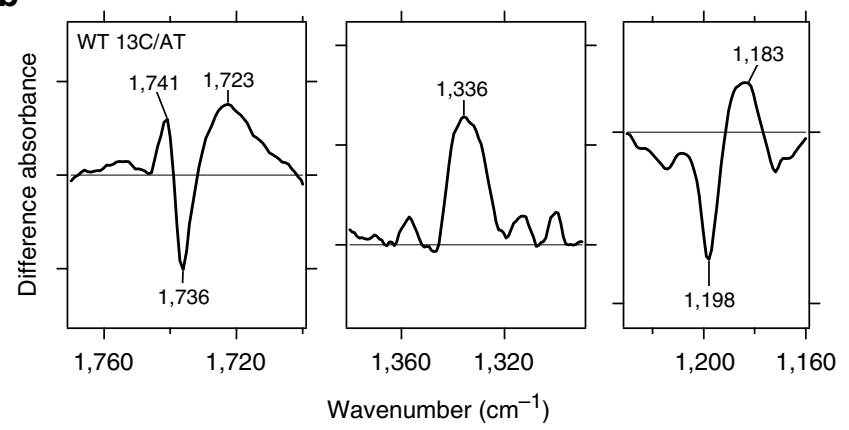

Figure 7 | Analysis of $\mathbf{H}^{+}$uptake in PoXeR. (a) Time-evolution of the accumulation of $\mathrm{M}$ intermediate at various $\mathrm{pH}$ values. (b) Light-induced difference FTIR spectra between $P_{0} X_{e} R_{13 C}$ and $P_{0} X_{e} R_{A T}$ states at $277 \mathrm{~K}$ and $\mathrm{pH}$ 8.0.

discovery of a light-driven inward $\mathrm{H}^{+}$pump will lead to better understanding of the molecular mechanism of light-driven pumps and contribute to the development of new optogenetic tools.

\section{Methods}

Protein expression and purification. Genes of $P o X e R, P o N a R$ and $P o C l R$, whose codons were optimized for an E. coli expression system, were synthesized (Eurofins Genomics Inc.) and subcloned into a pET21a $(+)$-vector with C-terminal $6 \times$ Histag. For mutagenesis, a QuikChange site directed mutagenesis kit (Stratagene) was used according to a standard protocol. Wildtype and mutant proteins were expressed in $E$. coli C43(DE3) strain. Protein expression was induced by $0.21 \mathrm{mM}$ isopropyl $\beta$ D-thiogalactopyranoside (IPTG) for $4 \mathrm{~h}$ at $37^{\circ} \mathrm{C}$ when $10 \mu \mathrm{M}$ all-trans-retinal (Sigma-Aldrich) was supplemented in the culture. The expressed proteins were purified from $E$. coli cells using previously reported protocols ${ }^{6,42-44}$. The cells were disrupted by a French Press (Ohtake) and the membrane fraction was collected by ultracentrifugation $(125,000 \mathrm{~g}, 1 \mathrm{~h})$. The protein was solubilized with $2 \% n$-dodecyl- $\beta$ D-maltoside (DDM) (Anatrace) in the presence of $300 \mathrm{mM} \mathrm{NaCl}, 5 \mathrm{mM}$ imidazole and $50 \mathrm{mM}$ MES (pH 6.5). After $\mathrm{Co}^{2+}{ }_{\text {-NTA affinity chromatography, the collected }}$ fractions were dialyzed against a solution containing $50 \mathrm{mM}$ Tris- $\mathrm{HCl} \mathrm{pH} \mathrm{8.0,}$ $100 \mathrm{mM} \mathrm{NaCl}, 0.1 \%$ DDM to remove imidazole used for the elution from a column.

Assay of light-driven ion-pumping activity of rhodopsins. E. coli cells expressing rhodopsins were collected by centrifugation $(4,800 \mathrm{~g}, 3 \mathrm{~min})$, washed three times with and resuspended in aqueous solution containing $100 \mathrm{mM}$ salt $\left(\mathrm{NaCl}, \mathrm{CsCl}\right.$ and $\left.\mathrm{Na}_{2} \mathrm{SO}_{4}\right)$. Cell suspension of $7.5 \mathrm{ml}$ at $\mathrm{OD}_{660}=2$ was placed in the dark and then illuminated at $\lambda>500 \mathrm{~nm}$ by a $1-\mathrm{kW}$ tungsten-halogen projector lamp (Rikagaku, Japan) through a glass filter (Y-52, AGC Techno Glass, Japan). For the blue-shifted PoXeR mutants (PoXeR D74E and D108E), light of $\lambda>460 \mathrm{~nm}$ (Y-48, AGC Techno Glass, Japan) was used for the photoexcitation. The light-induced $\mathrm{pH}$ changes were measured by a $\mathrm{pH}$ electrode (HORIBA, Japan). Measurements were repeated under the same conditions after the addition of $10 \mu \mathrm{M}$ CCCP.

Quantification of rhodopsins expressed in $\boldsymbol{E}$. coli. The amount of rhodopsin expressed in E. coli was estimated by a previously reported method ${ }^{6,43,44}$. E. coli cells expressing rhodopsins were collected by centrifugation at $3,600 \mathrm{~g}$ and $4{ }^{\circ} \mathrm{C}$ and

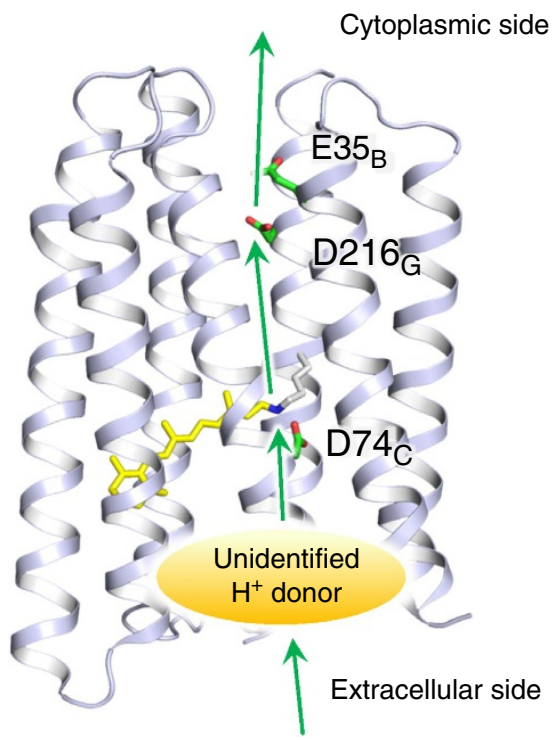

Figure 8 | Model for $\mathbf{H}^{+}$transfer pathway in PoXeR. The $\mathrm{H}^{+}$transfer pathway in PoXeR suggested by the results of the present study. The primary $\mathrm{H}^{+}$transfer occurs from the Schiff base to D216, and E35 affects this reaction. The Schiff base is not directly reprotonated from the aqueous phase, but there is an internal $\mathrm{H}^{+}$donor, yet to be identified.

suspended in a solution containing $100 \mathrm{mM} \mathrm{NaCl}$ and $50 \mathrm{mM}$ Tris- $\mathrm{HCl}(\mathrm{pH} \mathrm{8.0)}$ ), to a final volume of $3 \mathrm{ml}$. Then, $200 \mu \mathrm{l}$ of $1 \mathrm{mM}$ lysozyme was added to the suspension and it was gently stirred at room temperature for $1 \mathrm{~h}$. The E. coli cells were disrupted by sonication (TAITEC, Japan) and solubilized in 3.0\% DDM. The change in absorption, which represents the bleaching of rhodopsin by hydroxylamine (HA), was measured with a ultraviolet-vis spectrometer (Shimadzu, Japan) equipped with an integrating sphere after the addition of HA to a final concentration of $500 \mathrm{mM}$ and illumination at $\lambda>500 \mathrm{~nm}$ by a $1-\mathrm{kW}$ tungsten-halogen projector lamp (Rikagaku, Japan) through a glass filter (Y-52, AGC Techno Glass, Japan). The molecular extinction coefficient of WT PoXeR and mutant proteins $(\varepsilon)$ was calculated from the ratio between the absorbance of rhodopsin and retinal oxime $\left(\varepsilon=33,600 \mathrm{M}^{-1} \mathrm{~cm}^{-1}\right.$ at $360 \mathrm{~nm}$ (ref. 45) produced by the reaction between the retinal Schiff base and HA. The amount of protein expressed in E. coli cells was determined by the absorbance of the bleached rhodopsin. The transport activity of $E$. coli cells containing each rhodopsin was quantitatively determined from the initial slope of $\mathrm{pH}$ change after normalizing by the expression level of protein.

Measurement of dark-adaptation kinetics. Dark adaptation kinetics was measured for $0.1 \%$ DDM-solubilized sample at $24^{\circ} \mathrm{C}$. The dark-adapted sample was illuminated for $2 \mathrm{~min}$ by using output from a 1-kW tungsten-halogen projector lamp (Master HILUX-HR, Rikagaku, Japan) through a glass filter (O-60, AGC Techno Glass, Japan) at $\lambda>580 \mathrm{~nm}$. After turning off the light, the spectra or the absorption at a specific wavelength were measured every 1 min or $1 \mathrm{~s}$, respectively, by a ultraviolet-visible spectrometer (V-730, JASCO).

Heterologous expression in mammalian cells. A human codon-adapted PoXeR gene was synthesized by Gen Script (Piscataway, NJ, USA) and cloned into pEGFP vector between HindIII and BamHI sites. ND7/23 cells were purchased from DS Pharma Biomedical (Osaka, Japan) and cultured in high-glucose DMEM media (Wako) in a $37^{\circ} \mathrm{C}, 5 \% \mathrm{CO}_{2}$ incubator. Transfection of ND7/23 cells was performed by Lipofectamine 2000 (Invitrogen, Carlsbad, CA, USA). Cells were supplemented with $1 \mu \mathrm{M}$ all-trans-retinal (Sigma-Aldrich) after transfection. Expression was confirmed by a fluorescence microscope (IX-73, Olympus, Tokyo, Japan).

Electrophysiology. Whole cell patch clamp was performed with an amplifier, Axopatch 200B (Molecular Devices, Sunnyvale, CA, USA). Continuous light was provided by OSG L12194-00-39070 (Hamamatsu Photonics, Shizuoka, Japan) via a light guide into an inverted microscope, IMT-2 (Olympus, Tokyo Japan). Illumination was controlled by a mechanical shutter LS6S (Vincent Associates, Rochester, NY, USA). Glass pipettes were fabricated by a micropipette puller, P-97 (Sutter Instrument, Novato, CA, USA) and fire-polished by a micro forge, MF-830 (Narishige, Tokyo, Japan). The pipette resistance was $1.5-2.5 \mathrm{M} \Omega$. The pipette electrode was controlled by a micro manipulator, PCS-5000 (Burleigh instruments, Fishers, NY, USA). Current traces were recorded at $10 \mathrm{kHz}$ and filtered to $2 \mathrm{kHz}$ by 


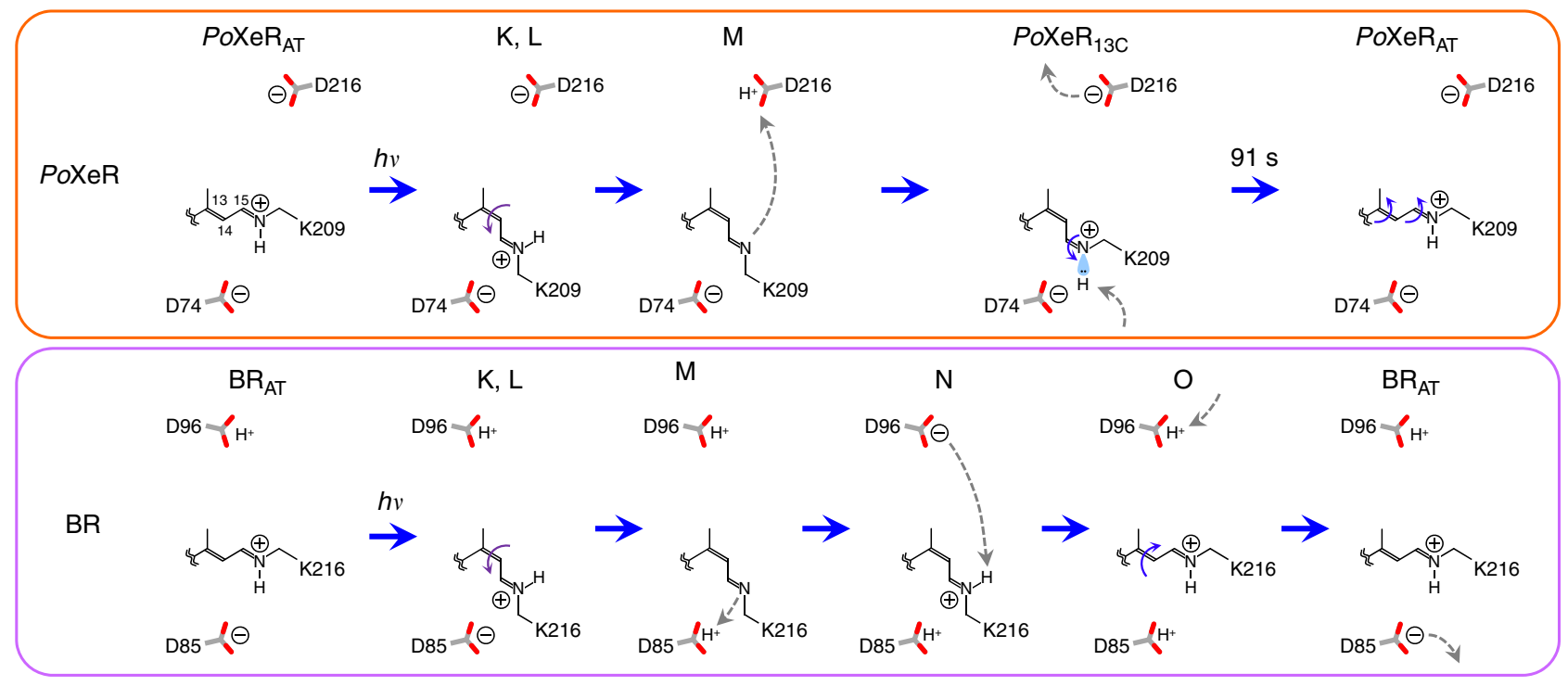

Figure 9 | Mechanism of inward $\mathbf{H}^{+}$transport in PoXeR and outward $\mathbf{H}^{+}$transport in BR. Schematic description of $\mathrm{H}^{+}$transport in the photocycle of PoXeR compared with the photocycle of $\mathrm{BR}$. In $\mathrm{BR}$, only one double bond at $\mathrm{C}_{13}=\mathrm{C}_{14}$ isomerizes during the outward $\mathrm{H}^{+}$pumping photocycle (trans to cis photoisomerization, and cis to trans thermal isomerization). In contrast, retinal isomerization is more complex to facilitate the inward $\mathrm{H}^{+}$pump in $P$ oXeR: (i) $\mathrm{C}_{13}=\mathrm{C}_{14}$ trans to cis photoisomerization, (ii) $\mathrm{C}_{15}=\mathrm{N}$ anti to syn thermal isomerization, and (iii) $\mathrm{C}_{13}=\mathrm{C}_{14}$ cis to trans and $\mathrm{C}_{15}=\mathrm{N}$ syn to anti thermal isomerization by a bicycle-pedal motion.

an internal circuit of the amplifier. Data acquisition and shutter triggering were performed by pClamp 10 software via a Digidata 1550 (Molecular Devices, Sunnyvale, CA, USA). Data were analysed by Clampfit 10 software.

The standard external solution contained $140 \mathrm{mM} \mathrm{NaCl}, 2 \mathrm{mM} \mathrm{MgCl}, 2 \mathrm{mM}$ $\mathrm{CaCl}_{2}, 2 \mathrm{mM} \mathrm{KCl}$ and $10 \mathrm{mM}$ HEPES-NaOH (pH 7.2). The standard internal solution contained $110 \mathrm{mM} \mathrm{NaCl}, 2 \mathrm{mM} \mathrm{MgCl} 2,1 \mathrm{mM} \mathrm{CaCl}_{2}, 5 \mathrm{mM} \mathrm{KCl}, 10 \mathrm{mM}$ EGTA and $10 \mathrm{mM}$ HEPES-NaOH (pH 7.2). Osmolality of the solutions was adjusted to $300 \mathrm{mOsm}$ by adding an appropriate amount of sucrose.

Preparation of PoXeR reconstituted in asolectin. For PoXeR reconstitutions in a lipid bilayer, we used a nanodisc protocol ${ }^{46-48}$. Briefly, PoXeR $(\sim 5 \mathrm{nM})$ solubilized in $0.1 \%$ DDM, membrane scaffold proteins (MSP1E3D1) (M7074, Sigma) $(\sim 30 \mu \mathrm{M})$ and asolectin $(11145$, Sigma $)(\sim 120 \mu \mathrm{g})$ were mixed in a solution containing $20 \mathrm{mM}$ HEPES (pH 7.4) and $100 \mathrm{mM} \mathrm{NaCl}$. The mixture was incubated for $1 \mathrm{~h}$ at $4{ }^{\circ} \mathrm{C}$ and then Bio-Beads SM-2 (Bio-Rad) $(60 \mathrm{mg}$ ) were added to remove the detergent. After mixing overnight at $4{ }^{\circ} \mathrm{C}$, Bio-Beads were removed by centrifugation at 14,000 r.p.m. and $4^{\circ} \mathrm{C}$ for $1 \mathrm{~min}$. The nanodisc products were purified by a $0.45 \mu \mathrm{m}$ syringe filter (Millipore).

High-speed AFM. In-house high-speed AFM operated in tapping mode was used $^{49,50}$. In high-speed AFM, the cantilever deflection is detected by an optical beam deflection detector using an infrared laser $(780 \mathrm{~nm})$. The laser beam is focused onto the back side of a cantilever covered by a gold film through a $\times 60$ objective lens (Nikon: CFI S Plan Fluor ELWD $60 \times$ ) and the reflected laser is detected by a two-segmented PIN photodiode. The size of a cantilever (Olympus: BL-AC7DS-KU4) is 6-7 $\mu \mathrm{m}$ long, $2 \mu \mathrm{m}$ wide, and $90 \mathrm{~nm}$ thick. A spring constant is estimated to be $0.1-0.2 \mathrm{~N} \mathrm{~m}^{-1}$ by a thermal method, and a resonant frequency and quality factor of a cantilever in liquid are $\sim 1 \mathrm{MHz}$ and $\sim 2$, respectively. The free oscillation amplitude was $\sim 1 \mathrm{~nm}$ and the set-point amplitude was about $90 \%$ of the free amplitude during the AFM observation. To gain a sharp probe, we deposited an amorphous carbon tip on the initial bird's beak tip by electron beam deposition. The length of an amorphous carbon tip was $\sim 500 \mathrm{~nm}$, and the end radius of the tip was $\sim 4 \mathrm{~nm}$. The AFM was performed under the buffer solution containing $20 \mathrm{mM}$ Tris- $\mathrm{HCl}(\mathrm{pH} 8.0)$ and $100 \mathrm{mM} \mathrm{NaCl}$ at room temperature.

HPLC analysis of retinal configuration. The configuration of retinal in PoXeR was analysed by high-performance liquid chromatograph (HPLC) as described previously ${ }^{17}$. A silica column $(6.0 \times 150 \mathrm{~mm}$; YMC-Pack SIL) was used for the analysis. We added HA (final conc. $500 \mathrm{mM}$ ) to $100 \mu \mathrm{l}$ PoXeR solution ( $100 \mathrm{mM}$ $\mathrm{NaCl}, 20 \mathrm{mM}$ Tris- $\mathrm{HCl}(\mathrm{pH} 8.0))$ at $4{ }^{\circ} \mathrm{C}$, and then the protein was denatured with $66 \%(\mathrm{v} / \mathrm{v})$ methanol. The retinal of PoXeR was released as retinal-oxime and extracted with hexane. The extracted sample was analysed by HPLC (solvent composition: $12 \%(\mathrm{v} / \mathrm{v})$ ethyl acetate and $0.12 \%(\mathrm{v} / \mathrm{v})$ ethanol in hexane) with $1.0 \mathrm{ml} \mathrm{min}^{-1}$ flow rate. The molar fraction of each retinal isomer was calculated from the ratio of the areas of corresponding peaks in the HPLC patterns. Each peak was assigned by comparison with the HPLC pattern of retinal oximes obtained from pure free all-trans- and 13-cis retinals. To analyse the retinal configuration of light-adapted PoXeR, the sample solution was illuminated with $\lambda>500 \mathrm{~nm}$ light (Y-52, AGC Techno Glass) for $1 \mathrm{~min}$ before the reaction with $\mathrm{HA}$ at $4{ }^{\circ} \mathrm{C}$. To estimate the experimental error, three identical measurements were performed for both dark- and light-adapted samples.

Laser flash photolysis. The time-evolution of the transient absorption changes of photo-excited PoXeR was observed as previously described ${ }^{6}$. The purified sample was resuspended in buffer containing $50 \mathrm{mM}$ Tris- $\mathrm{HCl}(\mathrm{pH} 8.0), 100 \mathrm{mM} \mathrm{NaCl}$ and $0.1 \%$ DDM. The sample solution was placed in a quartz cuvette and was excited with a beam of second harmonics of a nanosecond pulsed $\mathrm{Nd}^{3+}:$ YAG laser ( $\lambda=532 \mathrm{~nm}$, INDI40, Spectra-Physics). The excitation laser power was

$3 \mathrm{~mJ}$ pulse ${ }^{-1}$. Sample solution of $0.6 \mathrm{ml}$ was used for each measurement and was replaced by a fresh dark-adapted sample for every photoexcitation. The change in transient absorption after photoexcitation was obtained by observing the change of the intensity of monochromated output of a Xe arc lamp (L9289-01, Hamamatsu Photonics, Japan) passed through the sample by a photomultiplier tube (R10699, Hamamatsu Photonics, Japan). Transient absorption spectra were reconstructed from the time-evolution of the change in transient absorption at various wavelengths from 360 to $710 \mathrm{~nm}$ with 10 -nm intervals. The signals were globalfitted with a multi-exponential function and decay-associated spectra were obtained by plotting the pre-exponential factors against probed wavelengths.

Low-temperature difference FTIR spectroscopy. For FTIR spectroscopy, WT PoXeR and mutants were reconstituted into a mixture of POPE and POPG (molar ratio $=3: 1)$ with a protein-to-lipid molar ratio of 1:50 by removing DDM with BioBeads (SM-2, Bio-Rad). The reconstituted samples were washed three times with $1 \mathrm{mM} \mathrm{NaCl}$ and $2 \mathrm{mM}$ Tris- $\mathrm{HCl}(\mathrm{pH}$ 8.0). The pellet was resuspended in the same buffer, but the concentration was adjusted to $1.7 \mathrm{mg} \mathrm{ml}^{-1}$. A $60 \mu \mathrm{l}$ aliquot was placed onto a $\mathrm{BaF}_{2}$ window and dried with an aspirator. Low-temperature FTIR spectroscopy was applied to the films hydrated with $\mathrm{H}_{2} \mathrm{O}$ and $\mathrm{D}_{2} \mathrm{O}$ at 230 and $277 \mathrm{~K}$ as described previously ${ }^{10,51,52}$. For the formation of the $\mathrm{M}$ intermediate, samples were illuminated with $>500 \mathrm{~nm}$ light for $1 \mathrm{~s}$. To measure the difference infrared spectrum between $P_{0 X e R_{A T}}$ and $P o X e R_{13 C}$, the latter was accumulated with $>590$ $\mathrm{nm}$ light for $1 \mathrm{~min}$ and spectra were measured during illumination. For each measurement, 128 interferograms were accumulated, and 2-4 identical recordings were averaged.

Phylogenic analysis of rhodopsin genes. The amino-acid sequences of rhodopsins were aligned using MUSCLE programme ${ }^{53}$ after the removal of a weakly conserved interhelical loop, and $\mathrm{N}$ - and C-terminal extensions to increase the accuracy of alignment. The evolutionary history was inferred using the NeighborJoining method ${ }^{54}$. The optimal phylogenetic tree with the sum of branch length $=15.12577349$ was obtained. The percentage of replicate trees in which the 
associated taxa clustered together in the bootstrap test (1,000 replicates) were calculated $^{54}$. The tree is drawn to scale, with branch lengths in the same units as those of the evolutionary distances used to infer the phylogenetic tree. The evolutionary distances were computed using the Poisson correction method ${ }^{55}$ and the units are the number of amino-acid substitutions/site. The analysis involved 41 amino-acid sequences. All positions containing gaps and missing data were eliminated. There were a total of 126 positions in the final dataset. Evolutionary analyses were conducted in MEGA6 (ref. 56).

Data availability. The data that support the findings of this study are available from the corresponding author upon reasonable request. The structures of $\mathrm{BR}$ (PDB ID: 1MOL) and ASR (PDB ID: 1XIO) were used to highlight residues in transmembrane helices in Supplementary Fig. 1 and for illustrations purposes in Fig. 6 andFig. 8.

\section{References}

1. Ernst, O. P. et al. Microbial and animal rhodopsins: structures, functions, and molecular mechanisms. Chem. Rev. 114, 126-163 (2014).

2. Deisseroth, K. Optogenetics: 10 years of microbial opsins in neuroscience. Nat. Neurosci. 18, 1213-1225 (2015).

3. Oesterhelt, D. \& Stoeckenius, W. Rhodopsin-like protein from the purple membrane of Halobacterium halobium. Nat. New Biol. 233, 149-152 (1971).

4. Matsuno-Yagi, A. \& Mukohata, Y. Two possible roles of bacteriorhodopsin; a comparative study of strains of Halobacterium halobium differing in pigmentation. Biochem. Biophys. Res. Commun. 78, 237-243 (1977).

5. Schobert, B. \& Lanyi, J. K. Halorhodopsin is a light-driven chloride pump. J. Biol. Chem. 257, 10306-10313 (1982).

6. Inoue, K. et al. A light-driven sodium ion pump in marine bacteria. Nat. Commun. 4, 1678 (2013).

7. Nagel, G. et al. Channelrhodopsin-1: a light-gated proton channel in green algae. Science 296, 2395-2398 (2002).

8. Nagel, G. et al. Channelrhodopsin-2, a directly light-gated cationselective membrane channel. Proc. Natl Acad. Sci. USA 100, 13940-13945 (2003).

9. Govorunova, E. G., Sineshchekov, O. A., Janz, R., Liu, X. \& Spudich, J. L. Natural light-gated anion channels: a family of microbial rhodopsins for advanced optogenetics. Science 349, 647-650 (2015).

10. Kawanabe, A., Furutani, Y., Jung, K. H. \& Kandori, H. Engineering an inward proton transport from a bacterial sensor rhodopsin. J. Am. Chem. Soc. 131, 16439-16444 (2009).

11. Inoue, K. et al. Converting a light-driven proton pump into a light-gated proton channel. J. Am. Chem. Soc. 137, 3291-3299 (2015).

12. Vogt, A. et al. Conversion of a light-driven proton pump into a light-gated ion channel. Sci. Rep. 5, 16450 (2015).

13. Tang, K., Lin, D., Liu, K. \& Jiao, N. Draft genome sequence of Parvularcula oceani $\mathrm{JLT}_{2} 2013^{\mathrm{T}}$, a rhodopsin-containing bacterium isolated from deep-sea water of the Southeastern Pacific. Mar. Genom. 24, 211-213 (2015).

14. Jung, K. H., Trivedi, V. D. \& Spudich, J. L. Demonstration of a sensory rhodopsin in eubacteria. Mol. Microbiol. 47, 1513-1522 (2003).

15. Ugalde, J. A., Podell, S., Narasingarao, P. \& Allen, E. E. Xenorhodopsins, an enigmatic new class of microbial rhodopsins horizontally transferred between archaea and bacteria. Biol. Direct 6, 52 (2011).

16. Sineshchekov, O. A., Trivedi, V. D., Sasaki, J. \& Spudich, J. L. Photochromicity of Anabaena sensory rhodopsin, an atypical microbial receptor with a cis-retinal light-adapted form. J. Biol. Chem. 280, 14663-14668 (2005).

17. Kawanabe, A., Furutani, Y., Jung, K. H. \& Kandori, H. FTIR study of the photoisomerization processes in the 13-cis and all-trans forms of Anabaena sensory rhodopsin at $77 \mathrm{~K}$. Biochemistry 45, 4362-4370 (2006).

18. Kawanabe, A., Furutani, Y., Jung, K. H. \& Kandori, H. Photochromism of Anabaena sensory rhodopsin. J. Am. Chem. Soc. 129, 8644-8649 (2007).

19. Braiman, M. S. et al. Vibrational spectroscopy of bacteriorhodopsin mutants: light-driven proton transport involves protonation changes of aspartic acid residues 85,96 , and 212. Biochemistry 27, 8516-8520 (1988).

20. Gerwert, K., Hess, B., Soppa, J. \& Oesterhelt, D. Role of aspartae-96 in proton translocation by bacteriorhodopsin. Proc. Natl Acad. Sci. USA 86, 4943-4947 (1989).

21. Vogeley, L. et al. Anabaena sensory rhodopsin: a photochromic color sensor at 2.0 A. Science 306, 1390-1393 (2004).

22. Otto, H. et al. Aspartic acid-96 is the internal proton donor in the reprotonation of the Schiff base of bacteriorhodopsin. Proc. Natl Acad. Sci. USA 86, 9228-9232 (1989).

23. Balashov, S. P. et al. The two pKa's of aspartate- 85 and control of thermal isomerization and proton release in the arginine- 82 to lysine mutant of bacteriorhodopsin. Biochemistry 34, 8820-8834 (1995).

24. Rammelsberg, R., Huhn, G., Lubben, M. \& Gerwert, K. Bacteriorhodopsin's intramolecular proton-release pathway consists of a hydrogen-bonded network. Biochemistry 37, 5001-5009 (1998).
25. Bagley, K., Dollinger, G., Eisenstein, L., Singh, A. K. \& Zimanyi, L. Fourier transform infrared difference spectroscopy of bacteriorhodopsin and its photoproducts. Proc. Natl Acad. Sci. USA 79, 4972-4976 (1982).

26. Kawanabe, A., Furutani, Y., Yoon, S. R., Jung, K. H. \& Kandori, H. FTIR study of the L intermediate of Anabaena sensory rhodopsin: structural changes in the cytoplasmic region. Biochemistry 47, 10033-10040 (2008).

27. Mathies, R. A., Lin, S. W., Ames, J. B. \& Pollard, W. T. From femtosecond to biology: mechansim of bacteriorhodopsin's light-driven proton pump. Annu. Rev. Biophys. Biophys. Chem. 20, 491-518 (1991).

28. Krebs, M. P. \& Khorana, H. G. Mechanism of light-dependent proton translocation by bacteriorhodopsin. J. Bacteriol. 175, 1555-1560 (1993).

29. Lanyi, J. K. Understanding structure and function in the light-driven proton pump bacteriorhodopsin. J. Struct. Biol. 124, 164-178 (1998).

30. Haupts, U., Tittor, J. \& Oesterhelt, D. Closing in on bacteriorhodopsin: progress in understanding the molecules. Annu. Rev. Biophys. Biomol. Struct. 28, 367-399 (1999).

31. Heberle, J., Fitter, J., Sass, H. J. \& Büldt, G. Bacteriorhodopsin: the functional details of a molecular machine are being resolved. Biophys. Chem. 85, 229-248 (2000).

32. Kandori, H. Role of internal water molecules in bacteriorhodopsin. Biochim. Biophys. Acta 1460, 177-191 (2000).

33. Gerwert, K., Freier, E. \& Wolf, S. The role of protein-bound water molecules in microbial rhodopsins. Biochim. Biophys. Acta 1837, 606-613 (2014).

34. Bondar, A. N., Fischer, S., Smith, J. C., Elstner, M. \& Suhai, S. Key role of electrostatic interactions in bacteriorhodopsin proton transfer. J. Am. Chem. Soc. 126, 14668-14677 (2004).

35. Shi, L., Yoon, S. R., Bezerra, Jr A. G., Jung, K. H. \& Brown, L. S. Cytoplasmic shuttling of protons in Anabaena sensory rhodopsin: implications for signaling mechanism. J. Mol. Biol. 358, 686-700 (2006).

36. Bergo, V. B. et al. Conformational changes in the photocycle of Anabaena sensory rhodopsin: absence of the Schiff base counterion protonation signal. J. Biol. Chem. 281, 15208-15214 (2006).

37. Sineshchekov, O. A., Spudich, E. N., Trivedi, V. D. \& Spudich, J. L. Role of the cytoplasmic domain in Anabaena sensory rhodopsin photocycling: vectoriality of Schiff base deprotonation. Biophys. J. 91, 4519-4527 (2006).

38. Saito, K., Kandori, H. \& Ishikita, H. Factors that differentiate the H-bond strengths of water near the Schiff bases in bacteriorhodopsin and Anabaena sensory rhodopsin. J. Biol. Chem. 287, 34009-34018 (2012).

39. Warshel, A. Bicycle-pedal model for the first step in the vision process. Nature 260, 679-683 (1976).

40. Strambi, A., Durbeej, B., Ferre, N. \& Olivucci, M. Anabaena sensory rhodopsin is a light-driven unidirectional rotor. Proc. Natl Acad. Sci. USA 107, 2132221326 (2010).

41. Rost, B. R. et al. Optogenetic acidification of synaptic vesicles and lysosomes. Nat. Neurosci. 18, 1845-1852 (2015).

42. Muroda, K., Nakashima, K., Shibata, M., Demura, M. \& Kandori, H. Protein-bound water as the determinant of asymmetric functional conversion between light-driven proton and chloride pumps. Biochemistry 51, 4677-4684 (2012).

43. Kato, H. E. et al. Structural basis for $\mathrm{Na}^{+}$transport mechanism by a lightdriven $\mathrm{Na}^{+}$pump. Nature 521, 48-53 (2015).

44. Inoue, K., Nomura, Y. \& Kandori, H. Asymmetric functional conversion of eubacterial light-driven ion pumps. J. Biol. Chem. 291, 9883-9893 (2016).

45. Scharf, B., Pevec, B., Hess, B. \& Engelhard, M. Biochemical and photochemical properties of the photophobic receptors from Halobacterium halobium and Natronobacterium pharaonis. Eur. J. Biochem. 206, 359-366 (1992).

46. Bayburt, T. H., Grinkova, Y. V. \& Sligar, S. G. Self-assembly of discoidal phospholipid bilayer nanoparticles with membrane scaffold proteins. Nano Lett. 2, 853-856 (2002).

47. Denisov, I. G., Grinkova, Y. V., Lazarides, A. A. \& Sligar, S. G. Directed self-assembly of monodisperse phospholipid bilayer nanodiscs with controlled size. J. Am. Chem. Soc. 126, 3477-3487 (2004).

48. Sligar, S. G. Finding a single-molecule solution for membrane proteins. Biochem. Biophys. Res. Commun. 312, 115-119 (2003).

49. Uchihashi, T., Kodera, N. \& Ando, T. Guide to video recording of structure dynamics and dynamic processes of proteins by high-speed atomic force microscopy. Nat. Protoc. 7, 1193-1206 (2012).

50. Ando, T., Uchihashi, T. \& Scheuring, S. Filming biomolecular processes by high-speed atomic force microscopy. Chem. Rev. 114, 3120-3188 (2014).

51. Kandori, H. et al. Tight Asp-85-Thr-89 association during the pump switch of bacteriorhodopsin. Proc. Natl Acad. Sci. USA 98, 1571-1576 (2001).

52. Ono, H. et al. FTIR spectroscopy of a light-driven compatible sodium ion-proton pumping rhodopsin at 77 K. J. Phys. Chem. B 118, 4784-4792 (2014).

53. Edgar, R. C. MUSCLE: multiple sequence alignment with high accuracy and high throughput. Nucleic Acids Res. 32, 1792-1797 (2004). 
54. Saitou, N. \& Nei, M. The neighbor-joining method: a new method for reconstructing phylogenetic trees. Mol. Biol. Evol. 4, 406-425 (1987).

55. Zuckerkandl, E. \& Pauling, L. in Evolving Genes and Proteins (eds Bryson, V. \& Vogel, H. J.) 97-166 (Academic Press, 1965).

56. Tamura, K. et al. MEGA5: molecular evolutionary genetics analysis using maximum likelihood, evolutionary distance, and maximum parsimony methods. Mol. Biol. Evol. 28, 2731-2739 (2011).

\section{Acknowledgements}

This work was financially supported by grants from the Japanese Ministry of Education, Culture, Sports, Science and Technology to K.I. $(26708001,26115706,26620005)$ and to H.K. $(25104009,15 \mathrm{H} 02391)$.

\section{Author contributions}

K.I. and H.K. contributed to the study design. K.I. contributed to construction of mutant proteins and introduction to E. coli. K.I. conducted pumping activity measurement. S.I. measured FTIR spectra. Y.K. and K.I. conducted transient absorption measurement. S.P.T. conducted electrophysiological measurement. Y.N. quantified the amount of protein expression in E. coli. M.S. and T.U. conducted High-speed AFM imaging. K.I. and H.K. wrote the paper. All authors discussed and commented on the manuscript.

\section{Additional information}

Supplementary Information accompanies this paper at http://www.nature.com/ naturecommunications

Competing financial interests: The authors declare no competing financial interests.

Reprints and permission information is available online at http://npg.nature.com/ reprintsandpermissions/

How to cite this article: Inoue, K. et al. A natural light-driven inward proton pump. Nat. Commun. 7, 13415 doi: 10.1038/ncomms13415 (2016).

Publisher's note: Springer Nature remains neutral with regard to jurisdictional claims in published maps and institutional affiliations.

(c) (i) This work is licensed under a Creative Commons Attribution 4.0 International License. The images or other third party material in this article are included in the article's Creative Commons license, unless indicated otherwise in the credit line; if the material is not included under the Creative Commons license, users will need to obtain permission from the license holder to reproduce the material. To view a copy of this license, visit http://creativecommons.org/licenses/by/4.0/

C) The Author(s) 2016 